\title{
ZIRCONIUM MEDIATED HYDROGEN OUTDIFFUSION FROM p-GaN
}

\author{
E.Kaminska ${ }^{1}$, A.Piotrowska ${ }^{1}$, A. Barcz ${ }^{1,3}$, J.Jasinski $^{2}$, M. Zielinski ${ }^{3}$, K.Golaszewska ${ }^{1}$, \\ R.F.Davis ${ }^{4}$, E. Goldys ${ }^{5}$, K. Tomsia ${ }^{5}$ \\ ${ }^{1}$ Institute of Electron Technology, Al.Lotnikow 46, Warsaw, Poland, eliana @ite.waw.pl. \\ ${ }^{2}$ Institute of Experimental Physics, Warsaw University, Warsaw, Poland \\ ${ }^{3}$ Institute of Physics PAS, Warsaw, Poland, \\ ${ }^{4}$ Department of Material Science and Eng., NCSU, Raleigh, NC 27695-7907, USA \\ ${ }^{5}$ SMPCE, Macquarie University, Sydney NSW, Australia
}

\begin{abstract}
We have shown that Zr-based metallization can effectively remove hydrogen from the p-type GaN subsurface, which eventually leads to the formation of an ohmic contact. As the release of hydrogen starts at $\sim 900^{\circ} \mathrm{C}$, the thermal stability of the contact system is of particular importance. The remarkable thermal behavior of the $\mathrm{ZrN} / \mathrm{ZrB}_{2}$ metallization is associated to the microstructure of each individual $\mathrm{Zr}$-based compound, as well as to the interfacial crystalline accommodation.
\end{abstract}

\section{INTRODUCTION}

The role of hydrogen in the passivation and activation of dopants in MOCVD grown $\mathrm{GaN}$ is commonly recognized, however, experimental knowledge on its behavior remains still incomplete [1]. Recent interest in GaN-based devices has stimulated studies on p-type doping issues $[2,3]$ as well as the search for novel ohmic contacts. In particular, Murakami [4] recommended metals with high binding energies to hydrogen for making ohmic contacts to $\mathrm{p}$-type $\mathrm{GaN}$, and this idea has been experimentally verified with the use of $\mathrm{Ta} / \mathrm{Ti}$ contacts [5]. These contacts provided the lowest reported contact resistivity values $\left(3 \times 10^{-5} \Omega \mathrm{cm}^{2}\right.$ for hole concentration of $\left.7 \times 10^{17} \mathrm{~cm}^{-3}\right)$, but they quickly degraded.

The accumulation of hydrogen in areas of high defect density has been considered [6], it is therefore very likely that hydrogen could be gettered in the superficial layer of $\mathrm{p}-\mathrm{GaN}$. In consequence, the subsurface volume may be characterized by a free carrier concentration lower than the bulk. The present study explores the problem of the accumulation of hydrogen in the near-surface region of $\mathrm{p}-\mathrm{GaN}$ and the possibility of its removal by using $\mathrm{ZrN} / \mathrm{ZrB}_{2}$ metallization and annealing. Zirconium possesses one of the highest absorptive capabilities for hydrogen of metal hydride systems, while $\mathrm{ZrN}$ and $\mathrm{ZrB}_{2}$ are distinguished for their exceptional low resistivities and high melting points. The content of hydrogen was quantified using secondary ion mass spectrometry (SIMS), while the stability of $\mathrm{Zr}$-based caps on $\mathrm{GaN}$ under annealing has been examined using transmission electron microscopy (TEM) together with SIMS.

\section{EXPERIMENTAL PROCEDURE}

The samples used in this study were (0001) oriented, Mg-doped GaN epilayers, 0.5-2 $\mu \mathrm{m}$ thick, grown via MOCVD on undoped GaN, with AlN buffer films predeposited on $6 \mathrm{H}-\mathrm{SiC}$ or sapphire substrates. The hole concentration was 
$\mathrm{p}=1-5 * 10^{17} \mathrm{~cm}^{-3}$. Prior to insertion into the deposition chamber, the surface of GaN was etched in buffered HF, and dipped in $\mathrm{NH}_{4} \mathrm{OH}: \mathrm{H}_{2} \mathrm{O}$ (1:10).

Thin films of $\mathrm{Zr}-\mathrm{N}$ and $\mathrm{Zr}-\mathrm{B}$ were deposited by DC magnetron sputtering in $\mathrm{Ar}$ discharge, from $\mathrm{ZrN}(99.5 \%)$ and $\mathrm{ZrB}_{2}$ (99.5\%) targets, respectively. The process parameters were first optimized with regard to the stoichiometric composition of deposited films. Finally, a bilayer $\mathrm{ZrN} / \mathrm{ZrB}_{2}$ metallization of a thickness $(100 \mathrm{~nm}) /(100 \mathrm{~nm})$, sequentially deposited without breaking the vacuum, was used throughout this study. Heat treatments were carried out in a rapid thermal annealer (RTA), in flowing $\mathrm{N}_{2}$, at temperatures in the range $700-1150^{\circ} \mathrm{C}$ for time $30 \mathrm{~s}$. to $5 \mathrm{~min}$. During RTA the samples were protected by a piece of $\mathrm{GaN} / \mathrm{Al}_{2} \mathrm{O}_{3}$ as a proximity cap.

The evolution of the microstructure of $\mathrm{Zr}$-based films deposited on GaN, under annealing, was investigated by cross-sectional transmission electron microscopy (XTEM) and high resolution imaging (HREM) in JEOL 2000EX microscope. SIMS profiling was performed with a Cameca $6 \mathrm{~F}$ instrument using either oxygen or cesium primary beam.

The electrical characterization involved measuring the current-voltage characteristics and the specific contact resistance using circular transmission line method. A complementary study of electrical properties of $\mathrm{Zr}$-based contacts to n-type GaN $\left(\mathrm{n}=1 * 10^{17} \mathrm{~cm}^{-3}\right)$ has also been carried out.

\section{RESULTS}

\section{Microstructure and thermal stability of $\mathrm{GaN} / \mathrm{ZrN} / \mathrm{ZrB}_{2}$ system}

The as-deposited $\mathrm{ZrN}$ and $\mathrm{ZrB}_{2}$ films exhibit golden-yellow and pale-yellow color, respectively, characteristic of stoichiometric compounds. XTEM micrographs and corresponding SIMS profiles of as-deposited and annealed $\mathrm{GaN} / \mathrm{ZrN} / \mathrm{ZrB}_{2}$ structures are given in Fig. 1 and 2. The initial morphology of $\mathrm{ZrN}$ film is amorphous with islands of fine-grain polycrystalline material. $\mathrm{ZrB}_{2}$ film is amorphous. Annealing at $800^{\circ} \mathrm{C}$ causes partial crystallization of $\mathrm{ZrN}$ into elongated grains, whereas the microstructure of $\mathrm{ZrB}_{2}$ film does not change noticeably. The final morphology, after annealing at $1100^{\circ} \mathrm{C}$, of $\mathrm{ZrN}$ film is columnar, while the $\mathrm{ZrB}_{2}$ top layer reveals a fine-grained structure.

SIMS depth profiles of ${ }^{11} \mathrm{~B}^{+},{ }^{14} \mathrm{~N}^{+},{ }^{9} \mathrm{Zr}^{+},{ }^{90} \mathrm{Zr}^{14} \mathrm{~N}$ and ${ }^{69} \mathrm{Ga}^{+}$, measured using $\mathrm{O}_{2}{ }^{+}$primary beam, has been chosen to illustrate the in-depth structure of $\mathrm{GaN} / \mathrm{ZrN} / \mathrm{ZrB}_{2}$ contacts. In Fig.2.a., a relatively high value of ${ }^{90} \mathrm{Zr}^{14} \mathrm{~N}$ signal in $\mathrm{ZrB}_{2}$ layer is a result of ${ }^{90} \mathrm{Zr}^{14} \mathrm{~N}$ and ${ }^{94} \mathrm{Zr}^{10} \mathrm{~B}$ mass interference. Similarly, the high intensity of ${ }^{90} \mathrm{Zr}$ in GaN layer is probably due to the interference with gallium-nitrogen cluster - the 5 orders of magnitude decrease of the ${ }^{90} \mathrm{Zr}^{14} \mathrm{~N}$ profile in $\mathrm{GaN}$ near the interface region indicates that $\mathrm{Zr}$ does not penetrate significantly into GaN.
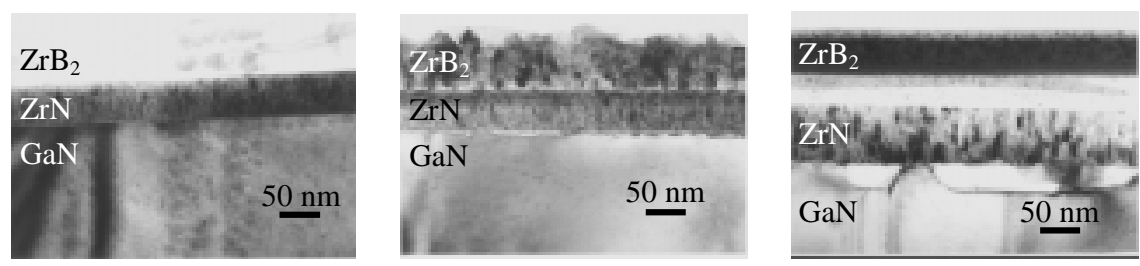

Figure 1. XTEM micrographs of $\mathrm{GaN} / \mathrm{ZrN} / \mathrm{ZrB}_{2}$ contact: a) as-deposited, b) annealed at $800^{\circ} \mathrm{C}, 5 \mathrm{~min}$., c) annealed at $1100^{\circ} \mathrm{C}, 30 \mathrm{~s}$. 

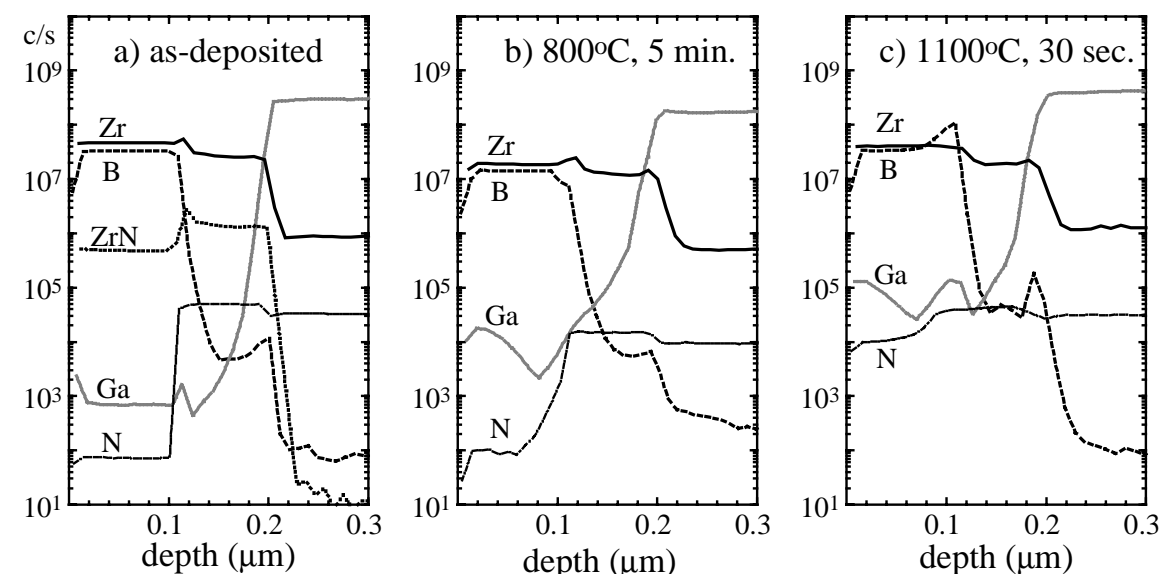

Figure 2. SIMS profiles for $\mathrm{GaN} / \mathrm{ZrN} / \mathrm{ZrB}_{2}$ contact: a) as-deposited, b) annealed at $800^{\circ} \mathrm{C}, 5 \mathrm{~min}$., c) annealed at $1100^{\circ} \mathrm{C}, 30 \mathrm{~s}$.

SIMS depth profiles of contacts unprocessed and heat treated at $800^{\circ} \mathrm{C}$ indicate that $\mathrm{GaN} / \mathrm{ZrN} / \mathrm{ZrB}_{2}$ system remains stable. In contacts subjected to annealing at $1100^{\circ} \mathrm{C}$, however, the $\mathrm{Ga}$ signal in $\mathrm{Zr}$-containing films increases about two orders of magnitude, suggesting that the interaction at the $\mathrm{GaN} / \mathrm{ZrN}$ interface has taken place.

In order to evaluate the extent of this interaction, in Fig. 3 are shown HREM images of $\mathrm{GaN} / \mathrm{ZrN}$ interfaces after annealing at $800^{\circ} \mathrm{C}$ and $1100^{\circ} \mathrm{C}$. While the interface of the contact processed at $800^{\circ} \mathrm{C}$ is sharp and abrupt, regular intrusions form at the $\mathrm{GaN} / \mathrm{ZrN}$ interface annealed at $1100^{\circ} \mathrm{C}$. High-resolution image and electron diffraction pattern revealed evidence for the formation of a new phase, lattice-matched to GaN. This phase, composed of $\mathrm{Ga}, \mathrm{Zr}$ and $\mathrm{N}$, as indicated by EDX analysis, could not be identified as yet.

\section{Hydrogen in GaN/ZrN/ZrB 2 system}

The behavior of hydrogen in $\mathrm{GaN} / \mathrm{ZrN} / \mathrm{ZrB}_{2}$ under annealing was studied with SIMS. Since $\mathrm{Zr}$ has a high affinity for hydrogen, it is obvious that some hydrogen is trapped in $\mathrm{Zr}$-based metallization during the sputter-deposition. In Table I are shown relative $\mathrm{H}^{-}$yields, with respect to $\mathrm{Zr}^{-}$ions, in $\mathrm{ZrN}$ and $\mathrm{ZrB}_{2}$ films as a function of annealing temperature. A noticeable evolution of hydrogen starts at $750^{\circ} \mathrm{C}$ from $\mathrm{ZrB}_{2}$ layer. After heat treatment at $850^{\circ} \mathrm{C}$ the $\mathrm{Zr}$-based metallization is practically free of hydrogen.

Table I. Relative $\mathrm{H}^{-}$yields with respect to $\mathrm{Zr}^{-}$in $\mathrm{ZrN}$ and $\mathrm{ZrB}_{2}$ films after annealing.

\begin{tabular}{|l|c|c|c|c|c|}
\hline $\begin{array}{l}\text { material/ } \\
\text { annealing }\end{array}$ & $\begin{array}{c}\text { as- } \\
\text { deposited }\end{array}$ & $\begin{array}{c}750^{\circ} \mathrm{C}, \\
5 \text { min. }\end{array}$ & $\begin{array}{c}800^{\circ} \mathrm{C}, \\
5 \text { min. }\end{array}$ & $\begin{array}{c}850^{\circ} \mathrm{C}, \\
5 \text { min. }\end{array}$ & $\begin{array}{c}1100^{0} \mathrm{C}, \\
30 \mathrm{~s} .\end{array}$ \\
\hline $\mathrm{ZrB} 2$ & 3.4 & 0.4 & 0.4 & 0.3 & 0.1 \\
\hline $\mathrm{ZrN}$ & 5.0 & 2.0 & 3.0 & 0.1 & 0.1 \\
\hline
\end{tabular}



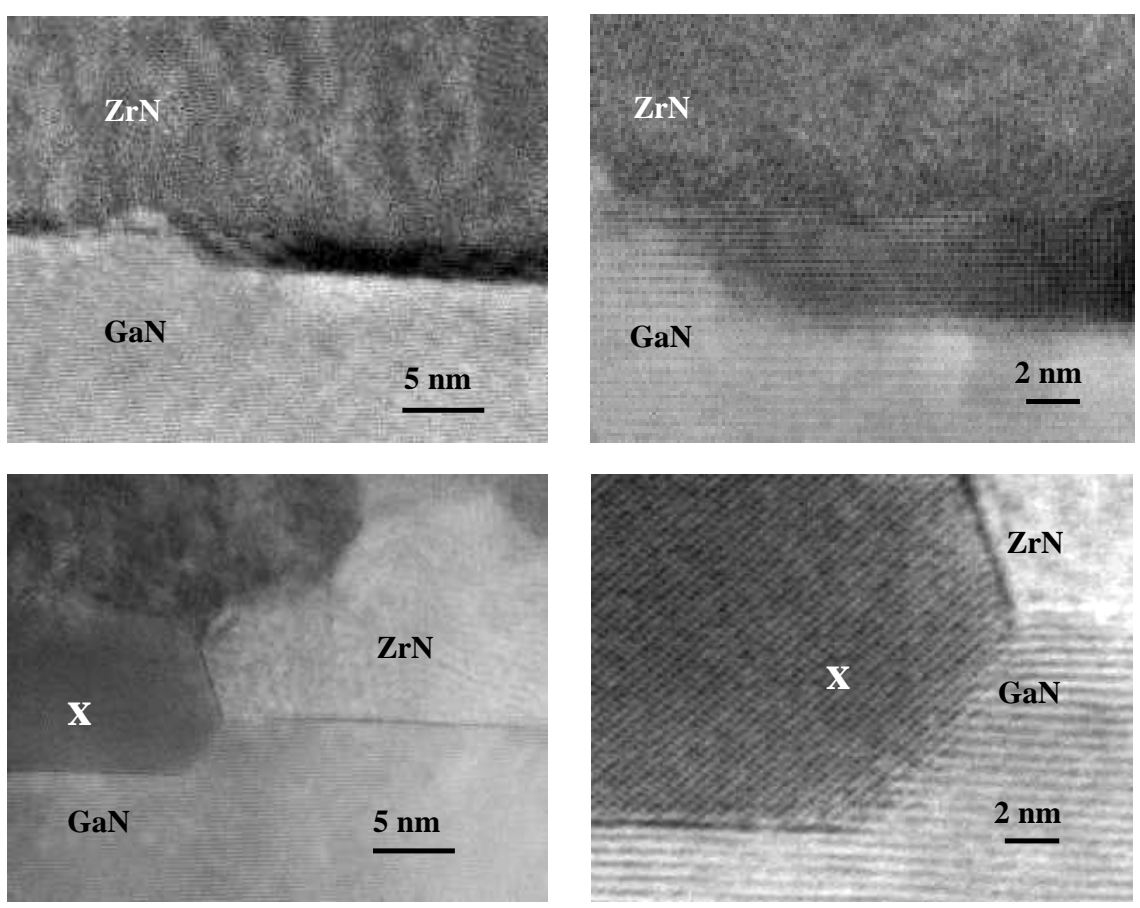

Figure 3. HREM images of $\mathrm{GaN} / \mathrm{ZrN}$ interface after annealing at: a) $800^{\circ} \mathrm{C}, 5 \mathrm{~min}$., b) $1100^{\circ} \mathrm{C}, 30 \mathrm{~s}$.

$\mathrm{Mg}$ and hydrogen depth profiles in $\mathrm{GaN}$ are presented in Fig.4. Concentrations of hydrogen and $\mathrm{Mg}$ in $\mathrm{GaN}$ were evaluated using relative sensitivity factors from ref. [7]. While the level of $\mathrm{Mg}$ in the entire layer of p-type $\mathrm{GaN}$ remains constant, a noticeably higher concentration of hydrogen in the near-surface region is clearly seen. For comparison, we have also analyzed the profile of hydrogen in $\mathrm{n}-\mathrm{GaN}$, confirming the absence of this impurity in n-type MOCVD-grown material with the detection limit $\sim 10^{17} \mathrm{~cm}^{-3}$. Heat treatment at $800^{\circ} \mathrm{C}$, i.e. at temperature effective for activation of $\mathrm{Mg}$ as a dopant [8], left the amount of hydrogen in p-type material practically unchanged. The process of evolution of hydrogen from the subcontact region starts at about $900^{\circ} \mathrm{C}$, and after annealing at $1100^{\circ} \mathrm{C}$ the level of this impurity in the subsurface layer of $\mathrm{p}-\mathrm{GaN}$ is substantially reduced, as demonstrated in Fig. 4.b.

\section{Electrical properties of $\mathrm{GaN} / \mathrm{ZrN} / \mathrm{ZrB}_{2}$ contacts}

The release of hydrogen from $\mathrm{p}-\mathrm{GaN}$ subsurface region perfectly correlates with the electrical properties of $\mathrm{GaN} / \mathrm{ZrN} / \mathrm{ZrB}_{2}$ contacts. Contacts annealed below $900^{\circ} \mathrm{C}$ are non-linear and highly resistive. After heat treatment at $900^{\circ} \mathrm{C}$ for $30 \mathrm{sec}$. they become linear. The minimum specific contact resistance of $1 * 10^{-4} \Omega \mathrm{cm}^{-3}\left(p=5 * 10^{17} \mathrm{~cm}^{-3}\right)$ was observed for contacts annealed at $1000^{\circ} \mathrm{C}$. Annealing at $1100^{\circ} \mathrm{C}$ causes the increase of 

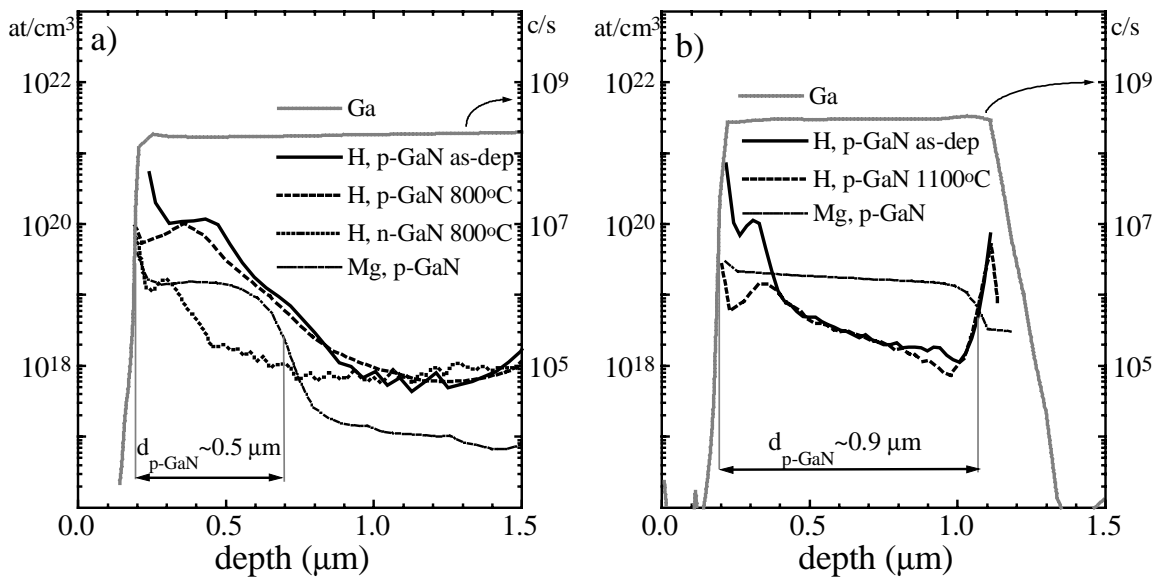

Figure 4. Magnesium and hydrogen depth profiles in $\mathrm{p}-\mathrm{GaN}$ annealed under $\mathrm{ZrN} / \mathrm{ZrB}_{2}$ : a) as-deposited and annealed at $800^{\circ} \mathrm{C}, 5 \mathrm{~min} .$, b) as-deposited and annealed at $1100^{\circ} \mathrm{C}, 30 \mathrm{~s}$.

the contact resistivity. Ohmic contacts formed at $1000^{\circ} \mathrm{C}$ were subjected to accelerated life-time testing at $600^{\circ} \mathrm{C}$ for 8 hours in $\mathrm{N}_{2}$ flow. Both, the low value of specific contact resistance and the surface morphology were preserved throughout the aging.

$\mathrm{ZrN} / \mathrm{ZrB}_{2}$ contacts, when deposited on n-type $\mathrm{GaN}$ become ohmic after heat treatment at $1100^{0} \mathrm{C}$ for $30 \mathrm{sec}$. with a resistivity of $6 * 10^{-4} \Omega \mathrm{cm}^{-3}\left(\mathrm{n}=1 * 10^{17} \mathrm{~cm}^{-3}\right)$.

\section{DISCUSSION AND CONCLUSIONS}

We have shown that $\mathrm{Zr}$-based metallization can effectively remove hydrogen from the p-type GaN subsurface which eventually leads to the formation of an ohmic contact. As the release of hydrogen starts at temperatures as high as $900^{\circ} \mathrm{C}$, the thermal stability of the contact system is of particular importance. The thermal behavior of the $\mathrm{ZrN} / \mathrm{ZrB}_{2}$ metallization is associated to the microstructure of each individual $\mathrm{Zr}$-based compound, as well as to the interfacial crystalline accommodation. Amorphous transition metal nitrides have been previously proven as effective diffusion barriers in integrated circuits technology [9], for thermal treatments up to $600^{\circ} \mathrm{C}$. In this work we demonstrate that by properly designing the configuration of the metallization system, the thermal stability of $\mathrm{Zr}$-based compounds can be enhanced well above their crystallization temperature. The use of $\mathrm{ZrB}_{2}$ layer on top of $\mathrm{ZrN}$ film effectively encapsulates the system, preventing the decomposition of the surface of $\mathrm{GaN}$ under annealing, even in case when the microstructure of $\mathrm{ZrN}$ film becomes columnar with grain boundaries providing the path for fast diffusion. On the other hand, $\mathrm{ZrN}$ interlayer between $\mathrm{GaN}$ and $\mathrm{ZrB}_{2}$ film impedes the recrystallization of the latter.

Whereas $\mathrm{Zr}$-based metallization enables hydrogen to outdiffuse from p-type subcontact region, the resistivity of ohmic contact increases, when the thermal processing is conducted at temperature $\sim 1100^{\circ} \mathrm{C}$, Our experiments clearly demonstrate that this coincides with a reaction at the contact interface. Thus the degradation of ohmic contact 
properties can be explained in terms of the decomposition of $\mathrm{GaN}$ and formation of nitrogen vacancies, being donors that compensate $\mathrm{Mg}$ acceptor centers. This would also explain the ohmic behavior, observed after heat treatment at $1100^{\circ} \mathrm{C}$, when the same metallization scheme is applied to n-type $\mathrm{GaN}$.

\section{ACKNOWLEDGEMENTS}

This work was partially supported by the Committee for Scientific Research, grant No. PBZ 28.11/P9.

\section{REFERENCES}

1. C.G. Van de Walle, N.M.Johnson, in Semiconductors and Semimetals 57 (Academic Press, 1999), Chap.4.

2. S. J. Pearton, J. W. Lee, in Semiconductors and Semimetals 61 (Academic Press, 1999), Chap.10.

3. J. Neugebauer, C.G. Van de Walle, J. Appl. Phys. 85, 3003 (1999).

4. M.Murakami, Y.Koide, Critical Rev. Sol. State Mat. 23, 1 (1998).

5. M. Suzuki, T. Kawakami, T. Arai, S. Kobayashi, Y. Koide, T. Uemura, N. Shibata, M. Murakami, Appl. Phys. Lett. 74, 275 (1999).

6. S.J. Pearton, S. Bendi, K. S. Jones, V. Krishnamoorthy, R. G. Wilson, R. F. Karlicek, Jr., R. A. Stall, Appl. Phys. Lett. 69, 1879 (1996).

7. J. W. Erickson, Y. Gao, R. G. Wilson, Mat. Res. Soc. Symp. Proc. Vol.395, 363 (1996).

8. W. Gotz, N. M. Johnson, J. Walker, D. P. Bour, R. A. Street, Appl. Phys. Lett. 68, 667 (1996).

9. L. Krusin-Elbaum, M. Wittmer, C-Y. Ting, J.J. Cuomo, Thin Solid Films 104, 81 (1983). 